\title{
A Simulation Model of Spray Flash Desalination System
}

\author{
Satoru Goto* Yuji Yamamoto* Takenao Sugi ** \\ Takeshi Yasunaga ${ }^{* *}$ Yasuyuki Ikegami ${ }^{* *}$ Masatoshi Nakamura* \\ * Department of Advanced Systems Control Engineering, Saga University \\ Honjomachi, Saga 840-8502, Japan \\ (Tel: +81-952-28-8643; Fax: +81-952-28-8666; \\ e-mail: goto@ee.saga-u.ac.jp) \\ ** Institute of Ocean Energy, Saga University \\ Honjomachi, Saga 840-8502, Japan
}

\begin{abstract}
In this paper, a simulation model of a spray flash desalination system is proposed. In the spray flash desalination system, the freshwater is made from the evaporation-condensation process, i.e., evaporation of warm surface seawater in a flash chamber and condensation of the generated vapor by deep cool seawater. A simulation model of the spray flash desalination system is constructed by using physical relations such as the energy conservation law and the mass conservation law. Simulation results of the proposed simulation model are compared with the experimental results of an experimental plant of the splay flash desalination system, and it shows the effectiveness of the proposed simulation model.
\end{abstract}

Keywords: spray flash; desalination system; simulation model; mass conservation law; energy conservation law

\section{INTRODUCTION}

Water issue is a serious problem in the world because of the influence of the rapid increase in population, global warming, climate change, etc. Many sectors have a keen interest in the desalination technology, which produces freshwater from almost inexhaustible seawater.

Multistage flash (MSF) process involving the multistage distillation of seawater at low pressure and reverse osmosis (RO) based on the separation of freshwater from seawater through a membrane at high pressure are the two main industrial processes used for desalination (Silver [1982], Kershman [2001]).

The MSF desalination is a wide-spread desalting method with a market share close to $55 \%$ of the total world production. Thermal desalination is based on evaporation of a strong saline seawater (brine) and condensation of the generated vapor. The vapor can be obtained either by heat addition (boiling) or by pressure reduction (flashing). The evaporation-condensation process is carried out in closed chambers (stages), which can be put in a chain leading to the MSF desalination process.

The RO desalination is a separation process by which seawater is separated into freshwater and concentrate (brine) water after passing the seawater over the surface of a semipermeable membrane under high pressure.

On the other hand, a spray flash desalination method has been proposed for the desalination process. Here, spray flash evaporation means that a superheated water jet is injected through nozzles into a relatively low pressure vapor zone. Spray flash evaporation releases from the evaporation restraint caused by liquid level, and it is a method of generating rapid and more complete evaporation. Even if the seawater temperature of the nozzle inflow is low, enough evaporation is obtained by using the spray flash evaporation. Since the spray flash desalination method can be generated freshwater with small temperature differences, the performance analysis of the hybrid cycle with Ocean Thermal Energy Conversion (OTEC) has been examined.

An OTEC system generates electricity by using $20-27\left[{ }^{\circ} \mathrm{C}\right]$ temperature difference between the $25-30\left[{ }^{\circ} \mathrm{C}\right]$ surface warm seawater and the 3-5 [ $\left.{ }^{\circ} \mathrm{C}\right]$ deep cold seawater. In opposition of the thermal power plants that use the fossil fuels such as oil, coal and natural gas, the heat source of the OTEC system is seawater warmed by the sun. Then, in the OTEC system, there is no incineration and no $\mathrm{CO}_{2}$ emission. Hence, the OTEC is environment-friendly and semi-permanent energy sources (Goto et al. [2006]).

There are two types of the OTEC systems of an open cycle system and a closed cycle system. Both types of the OTEC systems can generate freshwater as well as electricity.

In the open cycle OTEC system, surface warm seawater is partially evaporated at its vapor pressure. The vapor drives a turbine linked to a generator, and the worked vapor is then condensed in a condenser cooled by seawater from the deeper layers of the ocean. The non-condensed vapor is extracted from the condenser and vented to atmosphere, and the condensed vapor is used for potable freshwater production. Using surface condensers in which the vapor condenses on cold condenser tubes produces large quantities of desalinated water (Rey and Lauro [1981], Damy and Marvaldi [1987]).

In the closed cycle OTEC system, the surface warm seawater heats the working fluid when flowing through an evaporator. Then the deep cold seawater cools the working fluid when 


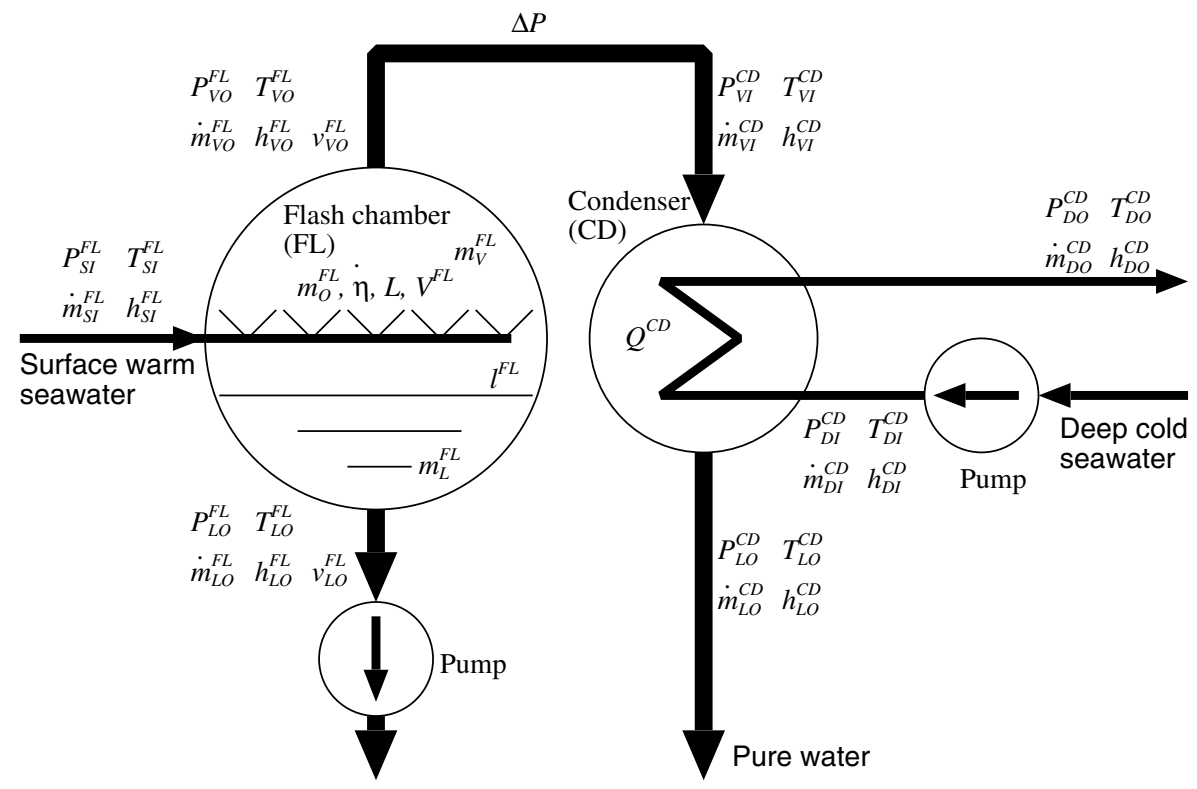

Fig. 1. Schematic diagram of spray flash desalination system

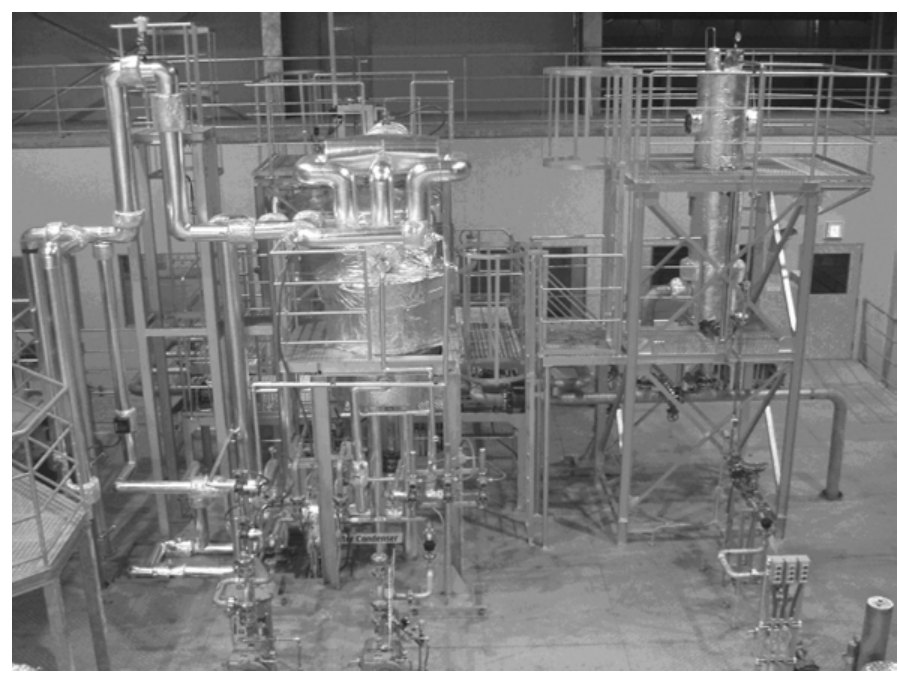

Fig. 2. Photograph of the experimental spray flash desalination plant (Ikegami et al [2006]).

flowing through a condenser. The surface warm seawater that flows into the flash chamber of the desalination system is from the outlet of the evaporator in the closed cycle OTEC system. Some water in the flash chamber evaporates under vacuum state. And the vapor enters in the condenser in the desalination system. At the condenser in the desalination system, the vapor is condensed to freshwater by the cool water from the outlet of the condenser in the closed cycle OTEC system. Furthermore, the power of the vacuum pump and the other pumps in the desalination system is also supplied by the closed cycle OTEC system.

In order to control the desalination plants, a dynamic model of the plants is required. For the MSF desalination system, a lot of researches such as a dynamic modelling of MSF desalination plants for automatic control and simulation purpose (Gambier and Badreddin [2004]), simulation and design of MSF desalination processes (Hamed and Aly [1994]), model reduction and robust control of MSF desalination plants (Ali et al. [2004]), an adaptive scheme with an optimally tuned PID controller for a MSF desalination plant (Woldai et al. [1996]) and modular structure simulation scheme of thermal desalination processes (Jernqvist et al. [2001]) have been done. For the spray flash desalination system, experimental studies (Ikegami et al [2006]) have been carried out, however, a dynamic model of a spray flash desalination system has not been developed.

In this paper, the simulation model for the spray flash desalination system is constructed. The spray flash desalination system can be modelled by using the energy conservation law and the mass conservation law. Simulation results of the model are compared with the experimental results and it shows the accuracy of the proposed simulation model. The developed simulation model can be applied to the design and control of spray flash desalination plants.

\section{SIMULATION MODEL OF DESALINATION SYSTEM}

\subsection{Spray Flash Desalination System}

Figure 1 shows the schematic diagram of the spray flash desalination system. The desalination process is described in the following three steps:

(1) The surface warm seawater flows into a depressurized flash chamber.

(2) The surface warm seawater evaporates instantly in the flash chamber.

(3) The vapor generated in the flash chamber is cooled and condensed by the deep cold seawater, and the freshwater can be obtained.

According to the above three steps, the freshwater is generated from the surface warm seawater.

Figure 2 shows an overview of the experimental desalination plant considered in this research. Seawater exchanges heat with the warm water supplied from the boiler in the seawater heat exchanger, and it is heated to the target temperature. It is then pumped up to the flash evaporator by the circulation pump. The superheated liquid is spouted upward upper part of the flash 
evaporator. The nonevaporated liquid is drained and most of the vapor condenses in a plate-type condenser. Then, a small amount of vapor is condensed in a shell and tube type auxiliary condenser, and the freshwater is conveyed into a freshwater tank.

In this research, the simulation model for a spray flash desalination plant is constructed. The object of the simulation model is the process of the freshwater generation, i.e., the evaporation of the warm seawater in flash chamber and the freshwater generation in the condenser cooled by the deep cold seawater.

\subsection{Purpose and Assumptions of Simulation Model}

Purpose The purpose and the input/output of the simulation model are determined (Wiener [1965]), after the object of the simulation model is fixed. The purposes of the simulation model are various, in this research, the simulation model is constructed, which can be used for the controller design and so on. Therefore, not only the static relation of the input/output but also the dynamic relation is necessary and relatively fast computing time is required.

Assumptions In order to construct the simulation model of the desalination system, the following assumptions are introduced.

(1) The heat transfer rate between the vapor and the cold seawater in the condenser originally depends both on the mass flow rate of the vapor and that of the deep cold seawater. Only the mass flow rate of the vapor is taken into account for the heat transfer rate under the assumption of the enough mass flow rate of the deep cold seawater.

(2) The temperature of the inlet vapor and that of the outlet freshwater of the condenser are the same.

(3) Ideal phase change at the saturated state occurs in the condenser.

(4) The pressure loss between the outlet of the flash chamber and the inlet of the condenser is constant.

(5) The mass flow rates of the vapor at the outlet of the flash chamber and that at the inlet of the condenser are the same, i.e., no time delay and no leakage of the vapor exist.

\subsection{Construction of Simulation Model}

Input and Output of Simulation Model The input/output of the simulation model which is suitable for the purpose of the simulation model, will be determined. In the desalination system, there are four inputs and two outputs. The four inputs are the mass flow rate of the surface warm seawater, that of the deep cold seawater, the temperature of the surface warm seawater and that of the deep cold seawater. The two outputs are the mass flow rate and the temperature of the generated freshwater. Table 1 shows the symbols used in the simulation model.

The variables which are used for the simulation model are determined, after the input/output of the simulation model is determined. The variables in the simulation model are categorized into the manipulated variables, the controlled variables, the disturbances and the state variables. The manipulated variables are the selected variables from the model inputs which can be manipulated. In the spray flash desalination system, the manipulated variables are the mass flow rate of the surface warm seawater and that of the deep cold seawater. The controlled variables are the selected variables from the model outputs which
Table 1. Nomenclature

(a) symbol

\begin{tabular}{c|l|c}
\hline & means & unit \\
\hline \hline$\dot{m}$ & mass flow rate & $\mathrm{kg} / \mathrm{s}$ \\
$T$ & temperature & ${ }^{\circ} \mathrm{C}$ \\
$P$ & pressure & $\mathrm{Pa}$ \\
$h$ & specific enthalpy & $\mathrm{J} / \mathrm{kg}$ \\
$v$ & specific volume & $\mathrm{m}^{3} / \mathrm{kg}$ \\
$c$ & specific heat & $\mathrm{J} /\left(\mathrm{kg}^{\circ} \mathrm{C}\right)$ \\
$U$ & heat transfer coefficient & $\mathrm{W} /\left(\mathrm{m}^{3}{ }^{\circ} \mathrm{C}\right)$ \\
$Q$ & heat transfer rate & $\mathrm{J} / \mathrm{s}$ \\
$V$ & volume & $\mathrm{m}^{3}$ \\
$L$ & specific latent heat & $\mathrm{J} / \mathrm{kg}$ \\
$\eta$ & efficiency & - \\
$l$ & liquid rate & - \\
$A$ & heat transfer area & $\mathrm{m}^{2}$ \\
\hline
\end{tabular}

(b) superscript

\begin{tabular}{l|l}
\hline & means \\
\hline \hline$F L$ & flash chamber \\
$C D$ & condenser \\
$P V$ & vacuum pump \\
\hline
\end{tabular}

(c) subscript

\begin{tabular}{c|l}
\hline & means \\
\hline \hline$I$ & inlet \\
$O$ & outlet \\
$V$ & vapor \\
$L$ & liquid \\
$Q$ & heat transfer rate \\
$S$ & surface warm seawater \\
$D$ & deep cold seawater \\
$S D$ & standard
\end{tabular}

agree with the control objective. In the spray flash desalination system, the controlled variable is the mass flow rate of the generated freshwater. The disturbances are the variables which affect to the controlled variable and can not be manipulated. In the spray flash desalination system, the disturbances are the temperature of the surface warm seawater and that of the deep cold seawater. The state variables are the variables which are necessary to represent the status of the model and in the desalination system, the state variables are mass flow rate, pressure, temperature, specific enthalpy, entropy, specific volume at each point of equipment.

Flash Evaporator The mass flow rate of the vapor generated in the flash chamber is derived by

$$
\dot{m}_{O}^{F L}=\eta \frac{\dot{m}_{S I}^{F L} c_{P}^{F L}\left(T_{S I}^{F L}-T_{V O}^{F L}\right)}{L}
$$

where $\eta$ is the efficiency of the freshwater production, $c_{P}^{F L}$ and $L$ are the specific heat and the latent heat of the water at the inlet of the flash chamber, respectively. The efficiency $\eta$ is determined by the plant property tests. The mass flow rate of the vapor exhausted from the flash chamber is derived by

$$
\dot{m}_{V O}^{F L}=\frac{Q^{C D}}{L}
$$

where $Q^{C D}$ is the heat transfer rate in the condenser. By applying the mass conservation law to the inlet and the outlets of the flash chamber, the mass flow rate of the vapor and the liquid in the flash camber are derived form eq.(1), eq.(2) and the flow rate of the warm seawater $\dot{m}_{S I}^{F L}$ as

$$
\frac{d m_{V}^{F L}}{d t}=\dot{m}_{O}^{F L}-\dot{m}_{V O}^{F L}
$$




$$
\frac{d m_{L}^{F L}}{d t}=\dot{m}_{S I}^{F L}-\dot{m}_{O}^{F L}-\dot{m}_{L O}^{F L}
$$

where $m_{V}^{F L}$ and $m_{L}^{F L}$ are the mass of the vapor and the liquid, respectively. From the energy conservation law in the flash evaporator, the relationship

$$
\frac{d\left(m_{V}^{F L} h_{V O}^{F L}+m_{L}^{F L} h_{L O}^{F L}\right)}{=\dot{m}_{S I}^{F L} h_{S I}^{F L}-\dot{m}_{V O}^{F L} h_{V O}^{F L}-\dot{m}_{L O}^{F L} h_{L O}^{F L}}
$$

is fulfilled and the specific enthalpy of the outlet liquid of the flash chamber $h_{L O}^{F L}$ is derived. Moreover, the specific volume of the fluid in the flash chamber $v_{V O}^{F L}$ is

$$
v_{V O}^{F L}=\frac{V^{F L}-m_{L}^{F L} v_{L O}^{F L}}{m_{V}^{F L}}
$$

and the liquid ratio in the flash chamber $l^{F L}$ is derived by

$$
l^{F L}=\frac{m_{L}^{F L} v_{L O}^{F L}}{V^{F L}} .
$$

The pressure at the outlet fluid of the flash chamber $P_{V O}^{F L}$ is derived from the the specific volume of the fluid in the flash chamber $v_{V O}^{F L}$ by PROPATH as

$$
P_{V O}^{F L}=f\left(v_{V O}^{F L}\right) .
$$

Condenser The mass flow rate of the fluid from the flash chamber to the condenser $\dot{m}_{V I}^{C D}$ is coincide with that of the outlet of the flash chamber $\dot{m}_{V O}^{F L}$ as

$$
\dot{m}_{V I}^{C D}=\dot{m}_{V O}^{F L}
$$

and the pressure at the inlet fluid of the condenser $P_{V I}^{C D}$ is derived from the pressure at the outlet fluid of the flash chamber $P_{V O}^{F L}$ and the pressure difference between the outlet of the flash chamber and the inlet of the condenser $\triangle P$ as

$$
P_{V I}^{C D}=P_{V O}^{F L}-\Delta P
$$

The heat transfer of the condenser is modelled by using the heat transfer coefficient and the logarithmic mean temperature. The heat transfer coefficient of the condenser $U^{C D}$ is obtained from the standard heat transfer coefficient $U_{S D}^{C D}$, the standard mass flow rate $\dot{m}_{S D}^{C D}$ and the mass flow rate of the inlet fluid of the condenser $\dot{m}_{V I}^{C D}$ as

$$
U^{C D}=U_{S D}^{C D}\left(\frac{\dot{m}_{V I}^{C D}}{\dot{m}_{S D}^{C D}}\right)^{0.5} .
$$

Here, the standard heat transfer coefficient $U_{S D}^{C D}$ and the standard mass flow rate $\dot{m}_{S D}^{C D}$ are the design values of the plant. The temperature of the inlet fluid of the condenser $T_{V I}^{C D}$ is derived by PROPATH as

$$
T_{V I}^{C D}=f\left(P_{I}^{C D}\right)
$$

under the assumption of the phase change from the vapor to the liquid at the saturation condition in the condenser, and the temperature of the inlet fluid and that of the outlet fluid at the condenser are assumed to be the same

$$
T_{L O}^{C D}=T_{V I}^{C D} \text {. }
$$

The logarithmic mean temperature difference is obtained by

$$
\Delta T^{C D}=\frac{\left(T_{V I}^{C D}-T_{D O}^{C D}\right)-\left(T_{L O}^{C D}-T_{D I}^{C D}\right)}{\ln \frac{T_{V I}^{C D}-T_{D O}^{C D}}{T_{L O}^{C D}-T_{D I}^{C D}}}
$$

and the heat transfer rate in the condenser $Q^{C D}$ is derived by

$$
Q^{C D}=U^{C D} A^{C D} \Delta T^{C D} \text {. }
$$

On the other hand, the heat transfer rate can be obtained from the deep cold seawater side as

$$
Q^{C D}=\dot{m}_{D I}^{C D} c_{P}^{C D}\left(T_{D O}^{C D}-T_{D I}^{C D}\right) .
$$

The temperature of the outlet seawater of the condenser $T_{D O}^{C D}$ is obtained such that both of the thfe heat transfer rate in the condenser $Q^{C D}$ eq.(15) and eq.(16) are the same. Finally the the heat transfer rate in the condenser $Q^{C D}$ is obtained from the derived temperature $T_{D O}^{C D}$. The mass flow rate of the freshwater from the condenser $\dot{m}_{L O}^{C D}$, the final output of the simulation model, is the same as the mass flow rate of the outlet fluid of the flash chamber $\dot{m}_{V O}^{F L}$, and is obtained by eq.(2).

\section{VALIDATION OF SIMULATION MODEL}

\subsection{Comparison between Experimental Results and Simulation Results}

The desalination plant used for the evaluation of the simulation model was the same as in (Ikegami et al [2006]). The size of the flash evaporator is diameter of $1.7[\mathrm{~m}]$, height of $3.184[\mathrm{~m}]$, volume of $6.0\left[\mathrm{~m}^{3}\right]$. The liquid and vapor temperature are measured by thermoresistances (Hayashi Electric Engineering, SR1, accuracy: \pm 0.1 ). The quantities of supply liquid from the nozzle in the flash chamber were measured using an electromagnetic flow meter (Tokyo Keiso, MGM1010K, accuracy: $\pm 0.50[\%])$. The pressure in the flash evaporator was measured with an absolute pressure sensor (Toshiba, AP3051CA, accuracy: $\pm 0.075[\%]$ ).

In the simulation model, the pressure difference between the outlet of the flash chamber and the inlet of the condenser was around $\Delta P=291.63[\mathrm{~Pa}]$. The efficiency of the freshwater production was derived by the previously obtained experimental data as $\eta=0.939$.

The simulation result of the proposed simulation model is compared with the experimental result of the actual pilot plant of the desalination system. Figure 3 shows an example of the comparison between the experimental data and the result of the simulation using the proposed simulation model. Fig. 3(a) (b) are the input conditions, (f) and (g) are the outputs.

The deviation of the freshwater temperature of the simulation result from the experimental result is less than $0.5\left[{ }^{\circ} \mathrm{C}\right](2.3[\%])$, and the deviation of the flash chamber pressure is less than $0.27[\mathrm{kPa}](10[\%])$. Because of manual operation of the valve of the freshwater tank, the mass flow rate of the experimental result was changing like stairs. On the other hand, the mass flow rate of the freshwater was almost constant in the simulation 
(a) Warm seawater temperature [DegC]

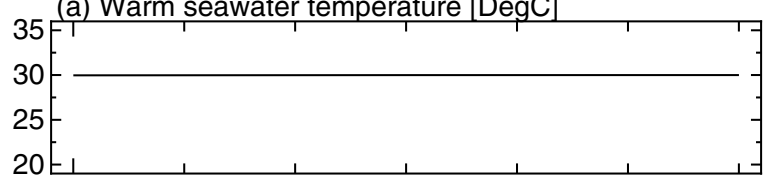

(b) Warm seawater flow rate $[\mathrm{kg} / \mathrm{s}]$

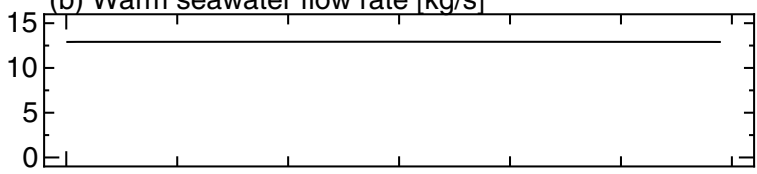

(c) Cold seawater temperature [DegC]

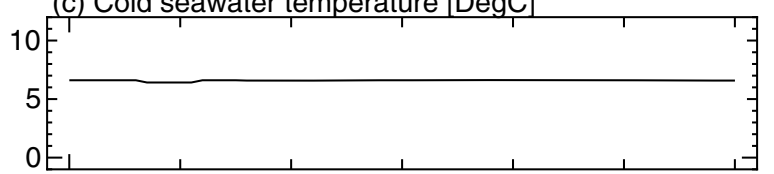

(d) Cold seawater flow rate $[\mathrm{kg} / \mathrm{s}]$
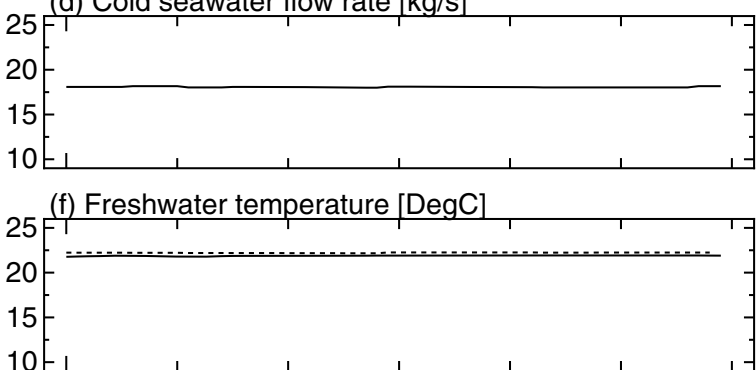

(g) Freshwater flow rate $[\mathrm{kg} / \mathrm{s}]$
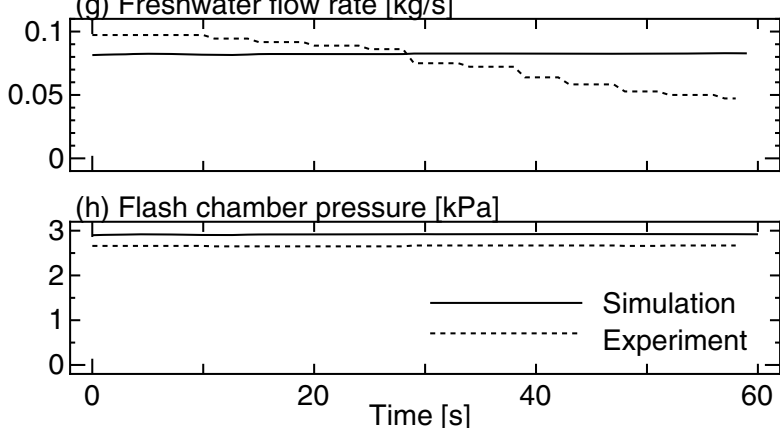

Fig. 3. Comparison between simulation results and experimental results

result. Also, the generation quantity of freshwater during the experimental time period was $4.58[\mathrm{~kg}]$ and it was $4.94[\mathrm{~kg}]$ in the simulation, and an error between the experimental result and the simulation result was $0.46[\mathrm{~kg}](10 \%)$.

\subsection{Simulation Results for Fluctuation of External Variables}

In the simulation result described in 3.1 , the external variables such as the warm seawater temperature and the cold seawater temperature were almost constant caused by the experimental condition. In order to verify that the proposed simulation model can be used for the fluctuated condition of the external variables, the simulation was carried out.

The fluctuation of the external variables, i.e., the temperature changes both of the warm seawater and the cold seawater were $2\left[{ }^{\circ} \mathrm{C}\right]$. In addition, the manipulated variables of the simulation model, i.e., the mass flow rate of the warm seawater and that of the cold seawater ware also changed.

Figure 4 shows the simulation result in which the mass flow rate of the surface warm seawater and that of the deep cold

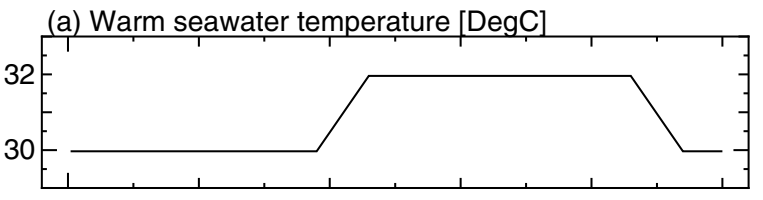

(b) Warm seawater flow rate $[\mathrm{kg} / \mathrm{s}]$

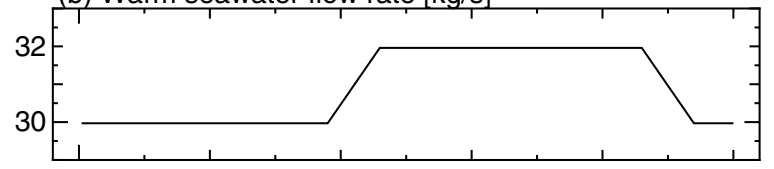

(c) Cold seawater temperature [DegC]

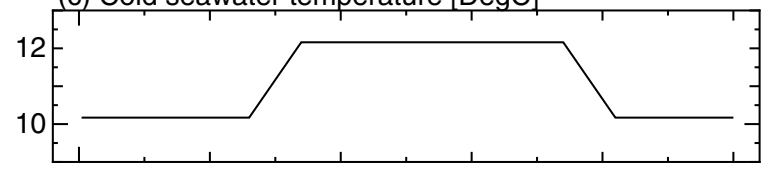

(d) Cold seawater flow rate $[\mathrm{kg} / \mathrm{s}$
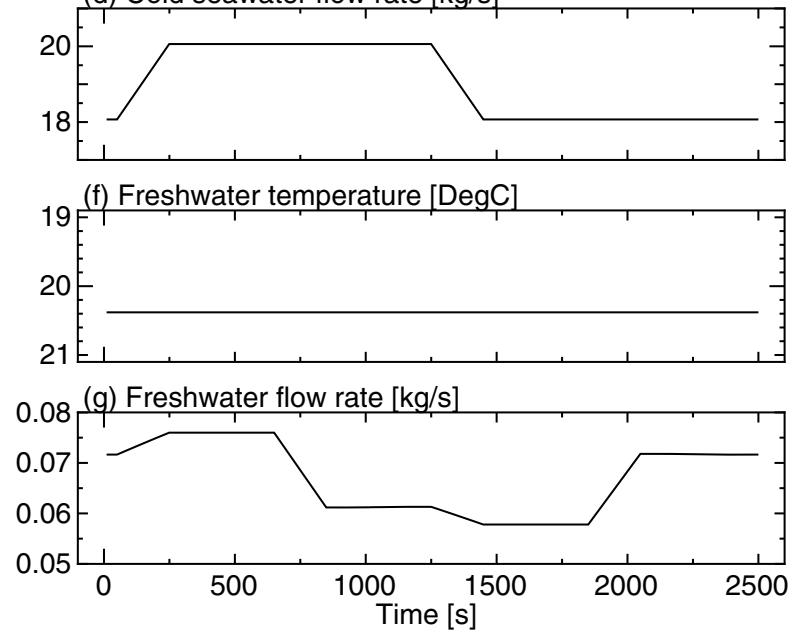

Fig. 4. Simulation results of expected variation condition

seawater were varied under the condition of changing the disturbances, i.e., the temperature of the surface warm seawater and that of the deep cold seawater. By using the simulation model, the simulation can be carried out under the changing condition of the manipulated variables and the disturbances. The result shows that the simulation model can derive not only the static relationship but also the dynamic relationship among the manipulated variables, the external variables and the output variables.

\section{DISCUSSION}

\subsection{Simulation Model}

The simulation model of the spray flash desalination system is based on the law of conservation of mass and the energy conservation law. As shown in 3.1, the proposed simulation model can express the characteristics of the actual plant appropriately. The deviation of the simulation result from the experimental result are caused by the assumptions described in 2.2 for the construction of the simulation model. The flash chamber pressure of the simulation result was higher than that of the experimental result, and the generation quantity of the fresh water of the simulation results was larger than that of the experimental result. One of the reasons is the ideal assumption of the flash chamber such as no leakage of the vapor. 
The dynamic property of the desalination plant was difficult to be derived, because of hardware problems of the experimental spray flash desalination plant. The dynamic property of the simulation model, however, had better be compared with the experimental results.

\subsection{Usage of Simulation Model}

The simulation model of the desalination system is applicable to the following usages.

(1) Simulator construction by using the simulation model: The proposed simulation model can be used for the various changes of the manipulated variables and the external variables, even if the changes are difficult to be applied to an actual plant. The simulator for training the operation of the spray flash desalination plant, hence, can be constructed by using the simulation model.

(2) Plant design based on the simulation model: The simulation model can easily confirm the status of the plant for various design conditions, hence, the plant design for various specifications can be implemented.

(3) Controller design based on the simulation model: Appropriate controller design for the the spray flash desalination plants is required. Systematic controller design can be achieved by using the simulation model.

\section{CONCLUSION}

A simulation model of a spray flash desalination system and examples of the simulation results were presented. The simulation model was based on the energy conservation law and the mass conservation law. By comparing the simulation results and the experimental results at some constant condition, the simulation model was able to express the property of the actual plant. The simulation result at the varying condition of the manipulated variables and the disturbances shows that the simulation model can be applied to the dynamic conditions. The simulation model of the desalination system is applicable to the simulator construction, the plant design and the controller design.

\section{ACKNOWLEDGEMENTS}

The authors would like to thank Mr. Taichi Ogawa, a master course student of the Department of Advanced Systems Control Engineering, Saga University for his simulation study.

\section{REFERENCES}

E. Ali, K. Alhumaizi, A. Ajbar: "Model Reduction and Robust Control of Multi-Stage Flash (MSF) Desalination Plants", Desalination, Vol. 121, pp. 65-85 (2004)

G. Damy and J. Marvaldi: "Some Investigation on the Possibility of Using Ocean Thermal Gradient (OTG) for Seawater Desalination", Desalination, Vol. 67, pp. 197-214 (1987)

A. Gambier and E. Badreddin: "Dynamic Modelling of MSF Plants for Automatic Control and Simulation Purposes: a Survey", Desalination, Vol. 166, pp. 191-204 (2004)

S. Goto, Y. Yamamoto, Y. Motoshima, T. Sugi, Y. Ikegami and M. Nakamura: "A Simulation Model for OTEC Plant Using Uehara Cycle", Proceedings of the Renewable Energy 2006 (RE'06), O-Oc-2-2, pp. 1407-1410 (2006-10)

O. A. Hamed and S. Aly: "Simulation and Design of MSF Desalination Processes", Desalination, Vol. 80, pp. 1-14 (1994)
Y. Ikegami, H. Sasaki, T. Gouda and H. Uehara: "Experimental Study on a Spray Flash Desalination (Influence of the Direction of Injection)" Desalination, Vol. 194, pp. 81-89 (2006)

A. Jernqvist, M. Jernqvist and G. Aly: "Simulation of Thermal Desalination Processes", Desalination, Vol. 134, pp. 187-193 (2001)

S. A. Kershman: "25 Years of Experience in Operating Thermal Desalination Plants", Desalination, Vol. 136,pp. 141-145 (2001)

Propath Group: http://gibbs.mech.kyushu-u.ac.jp/propath/

M. Rey and F. Lauro: "Ocean Thermal Energy and Desalination", Desalination, Vol. 39, pp. 159-168 (1981)

R. S. Silver: "Technological and Environmental Aspects of Desalination", Desalination, Vol. 42, pp. 1-9 (1982)

N. Wiener: Cybernetics: or Control and Communication in the Animal and the Machine, second Edition, MIT Press (1965)

A. Woldai, D. M. K. Al-Gobaisi, R. W. Dunn, A. Kurdali and G. P. Rao: "An Adaptive Scheme with an Optimally Tuned PID Controller for a Large MSF Desalination Plant", Control Engineering Practice, Vol. 4, No. 5, pp. $721-734$ (1996) 